\section{The influence of the} new general ophthalmic services (GOS) contract in optometrist referrals for glaucoma in Scotland
GS Ang, WS Ng and A Azuara-Blanco

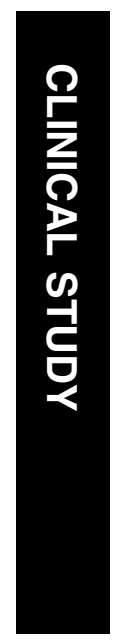

there has been an improvement in the quality of the glaucoma referrals from the community optometrists in the northeast of Scotland, with a corresponding reduction in false-positive referrals. Despite the relatively positive effect so far, there is still scope for further improvement.

Eye (2009) 23, 351-355; doi:10.1038/sj.eye.6703045; published online 30 November 2007

Keywords: optometrist; glaucoma; applanation tonometry; visual fields; fundoscopy

\section{Introduction}

Glaucoma is a leading cause of blindness worldwide and is a major public health concern. In the United Kingdom, the government aims to transfer a significant proportion of glaucoma management, currently performed by the Hospital Eye Service (HES), to the community and primary care. ${ }^{1}$ On 1 April 2006, a new General Ophthalmic Services (GOS) contract for National Health Service (NHS) primary ophthalmic care by the community optometrists was implemented in Scotland as part of the Smoking, Health and Social Care (Scotland) Act. One of the key aims of the New NHS Eye Examination by optometrists under the new GOS contract was to reduce inappropriate referrals to the HES, through the introduction of supplementary examinations, such as contact applanation tonometry, dilated indirect fundoscopy, and threshold automated perimetry (http://www.optometryscotland. org.uk/article.php?id = 20; accessed September 2007). It has been shown that the positive
Department of Ophthalmology, NHS Grampian, Aberdeen Royal Infirmary, Aberdeen, Scotland, UK

Correspondence: GS Ang, Department of Ophthalmology, NHS Grampian, Aberdeen Royal Infirmary, Eye Clinic, Foresterhill, Aberdeen, Scotland AB25 2ZN, UK

Tel: + 441224553214 ; Fax: + 441224553213 .

E-mail: gsang1@

doctors.org.uk

Received: 6 August 2007 Accepted in revised form: 27 October 2007 Published online: 30 November 2007

Proprietary interests/ Research funding: Nil for all authors 
predictive value of optometrist referrals tends to be higher when the intraocular pressure (IOP), visual field (VF), and optic disc were all assessed. ${ }^{2,3}$ Under the new GOS contract, community optometrists throughout Scotland were required to be accredited through attending workshops for the four basic competencies: applanation tonometry, slit lamp biomicroscopy, threshold VFs, and Volk lens indirect ophthalmoscopy (http:/ / www.optometryscotland.org.uk/ article.php?id =6; accessed September 2007).

Accreditation under the new GOS contract is mandatory for community optometrists wishing to practise in Scotland.

The aim of our study is to assess the impact of the new GOS contract on community optometrist referrals to the hospital glaucoma service in Aberdeen Royal Infirmary.

\section{Materials and methods}

Community optometrist referral forms and the initial glaucoma assessment sheets for all new patients referred to the Aberdeen Royal Infirmary glaucoma service were reviewed retrospectively. Two 6-month periods, the first from 1 June to 30 November 2005 (before the implementation of the new GOS contract), and the second from 1 June to 30 November 2006 (after the implementation of the new GOS contract), were selected for comparison.

In this study, patients were classified as having either:

(1) Glaucoma - characteristic optic disc and/or visual field changes

(2) Glaucoma suspect - inability to categorise either eye as definitely glaucoma or no glaucoma, regardless of intraocular pressure

(3) Ocular hypertension - raised IOP but normal visual fields and optic discs

(4) Normal

The main outcome measures were the false-positive and true-positive rate of the community optometrist referrals before and after the new GOS contract. A falsepositive referral was defined as one that was found to be normal and was discharged back to the community after the first hospital glaucoma service assessment. A truepositive referral was defined as one that was found to have glaucoma (ie, definite glaucomatous damage as defined above) during the first hospital glaucoma service assessment.

The secondary outcome measure was the proportion of community optometrist referrals that fulfilled the new GOS contract requirements - referrals should include information on applanation IOP, VF assessment, and optic disc evaluation - before and after the new GOS contract. As an extra measure of a good-quality referral, we also looked at the proportion of community optometrist referrals that included information on past ophthalmic history, family history of glaucoma, repeated IOP and VF assessments on two separate occasions, central corneal thickness measurements, and gonioscopic evaluation.

For the purposes of this study, we used data from the eye that the community optometrist felt had features suspicious for glaucoma. If both eyes had suspicious features, then data from the eye with the higher IOP were used. Basic descriptive statistics were used to analyse the main outcome measures as above. When comparing proportions between the two groups (before and after the new GOS contract), the $\chi^{2}$-test was used. When comparing means, the independent $t$-test was used. $P$-values of less 0.05 were considered statistically significant.

\section{Results}

A total of 303 referrals were made to the hospital glaucoma service by community optometrists during the study periods. 183 referrals were made during the first 6-month period before the implementation of the new GOS contract. 120 referrals were made during the second 6-month period after the implementation of the new GOS contract. Table 1 summarises the demographic characteristics for the two 6-month study periods. There were no statistically significant differences between the study periods in terms of demographics, IOP, and bestcorrected visual acuity (VA).

Table 2 characterises the outcome of the community optometrist referrals to the hospital glaucoma service. After the introduction of the new contract, there was a statistically significant increase in the number of true-positive referrals, the proportion of patients being started on topical IOP-lowering medication, and the proportion of patients requiring further follow-up by the hospital glaucoma service. There was also a statistically significant decrease in the number of false-positive referrals, referrals for OHT, and patients discharged after the first visit.

Table 3 compares the quality of the community optometrist referrals in the two 6-month study periods. We looked at the new GOS contract requirements and additional measures of quality that were not required in the new GOS contract, such as documentation of family history of glaucoma, gonioscopy, and corneal pachymetry. None of the referrals had gonioscopy or corneal pachymetry. After the implementation of the new GOS contract, there was a statistically significant improvement in the number of referrals with applanation IOPs $(P=0.000)$, dilated fundal examination $(P=0.000)$, and repeat VFs $(P=0.004)$. However, the proportion of 
Table 1 Demographic characteristics of referred patients during the two 6-month study periods before and after the implementation of the new GOS contract

\begin{tabular}{lccc}
\hline & $\begin{array}{c}\text { Before the new GOS } \\
\text { contract }(\mathrm{n}=183)\end{array}$ & $\begin{array}{c}\text { After the new GOS } \\
\text { contract }(\mathrm{n}=120)\end{array}$ & $\begin{array}{c}\text { Significance } \\
\text { Mean age (years) }\end{array}$ \\
Mean SE (dioptres) & $62.4 \pm 13.5 \mathrm{SD}$ & $65.4 \pm 13.8 \mathrm{SD}$ & 0.507 \\
Mean referral IOP (mmHg) & $24.0 \pm 7.4 \mathrm{SD}$ & $-0.3 \pm 3.2 \mathrm{SD}$ & 0.109 \\
Number of females $(\%)$ & $81(44.3 \%)$ & $22.7 \pm 7.2 \mathrm{SD}$ & 0.128 \\
\hline
\end{tabular}

$\mathrm{GOS}=$ general ophthalmic services; $\mathrm{IOP}=$ intraocular pressure; $\mathrm{mmHg}=$ millimetre mercury; $\mathrm{SD}=$ standard deviation; $\mathrm{SE}=$ spherical equivalent.

Table 2 Outcome of community optometrist referrals before and after the implementation of the new GOS contract

\begin{tabular}{lccc}
\hline & $\begin{array}{c}\text { Before the new } \\
\text { GOS contract }(\mathrm{n}=183)\end{array}$ & $\begin{array}{c}\text { After the new } \\
\text { GOS contract }(\mathrm{n}=120)\end{array}$ & $\begin{array}{c}\text { Significance } \\
\text { Number of community optometrist }\end{array}$ \\
$\begin{array}{l}\text { referrals for ocular hypertension (\%) } \\
\text { False-positive referrals (\%) }\end{array}$ & $54(29.5 \%)$ & $9(7.5 \%)$ & 0.000 \\
True-positive referrals (\%) & $67(36.6 \%)$ & $26(21.7 \%)$ & 0.006 \\
Number started on IOP lowering drops (\%) & $33(18.3 \%)$ & $36(31.7 \%)$ & 0.006 \\
Number discharged after the first visit (\%) & $34(18.6 \%)$ & $20(16.7 \%)$ & 0.021 \\
Number requiring further follow-up by & $79(43.2 \%)$ & $43(35.8 \%)$ & 0.004 \\
the hospital glaucoma service $(\%)$ & $43(23.5 \%)$ & & 0.020 \\
\hline
\end{tabular}

$\mathrm{GOS}=$ general ophthalmic services; IOP $=$ intraocular pressure.

Table 3 The quality of community optometrist referrals before and after the implementation of the new GOS contract

\begin{tabular}{lcrc}
\hline & $\begin{array}{c}\text { Before the new GOS } \\
\text { contract }(\mathrm{n}=183)\end{array}$ & $\begin{array}{c}\text { After the new } \\
\text { GOS contract }(\mathrm{n}=120)\end{array}$ & $\begin{array}{c}\text { Significance } \\
\text { Number with IOP repeated (\%) }\end{array}$ \\
Number with applanation tonometry (\%) & $60(32.8 \%)$ & $51(42.5 \%)$ & 0.086 \\
Number with optic disc assessment (\%) & $18(11.8 \%)$ & $60(50.0 \%)$ & 0.000 \\
Number with dilated fundal examination (\%) & $172(94.0 \%)$ & $103(85.8 \%)$ & 0.017 \\
Number with visual fields (\%) & $4(2.2 \%)$ & $111(92.2 \%)$ & 0.000 \\
Number with repeated visual fields (\%) & $163(89.1 \%)$ & $34(28.3 \%)$ & 0.072 \\
Number with documentation of family history (\%) & $27(14.8 \%)$ & $31(25.8 \%)$ & 0.004 \\
Number fulfilling new GOS contract criteria (\%) & $67(36.6 \%)$ & $50(41.7 \%)$ & 0.050 \\
\hline
\end{tabular}

$\mathrm{GOS}=$ general ophthalmic services; $\mathrm{IOP}=$ intraocular pressure.

referrals with optic disc assessment and documentation of family history of glaucoma were statistically significantly lower $(P=0.017$ and 0.050 , respectively). Less than half (41.7\%) fulfilled the new GOS (Scotland) contract requirements. The most common examination missing in the referral was applanation tonometry.

\section{Discussion}

There have already been previous reports in the United Kingdom about the outcomes of optometrist referrals to the HES. ${ }^{2,4-6}$ In these studies, the false-positive rate was as high as $57 \%$, with up to $45 \%$ discharged from the HES at the first visit. ${ }^{2,4,5}$ Patients with confirmed glaucomatous damage only made up approximately
$17-20 \%$ of the optometrist referrals. ${ }^{2,4,5} \mathrm{Up}$ to $12 \%$ of optometrist referrals were made for isolated VF loss in the absence of any glaucoma damage. ${ }^{7,8}$ A separate study reported an increase in false-positive referrals from 1988 to 1993, and this was felt to be due to the increase in VF testing and to an increased willingness to refer patients at lower IOPs. ${ }^{6}$

As referrals have been shown to be more accurate when IOP measurement, VF testing, and optic disc assessment were all performed, ${ }^{2,3}$ it was important that any glaucoma detection programme involving optometrists should involve all three parameters. From previous papers, the reported proportion of referrals containing information for these three parameters ranged from 15 to $82 \% .^{2,3,8}$ To further increase the positive 
predictive value of referrals, it has also been recommended that IOP measurements and visual fields should be repeated. ${ }^{3}$

Under the old GOS contract, when patients attended their community optometrist, refraction was mandatory, and there was no provision for supplemental examinations such as applanation tonometry and perimetry, to be performed regardless of clinical need. The new GOS contract intended for the community optometrist to act as a gateway for ophthalmic care in the Scottish NHS. With optometry premises located in most communities throughout Scotland, it was envisaged that the new contract would allow patients with any eye complaints to access NHS eye care at their local optometrist, thereby relieving the burden on general practitioners as well as on the HES. The new GOS contract does not require mandatory refraction, and allows community optometrists to carry out tests that are appropriate for the patient. It is envisaged that this will improve the quality of referrals to secondary care, and greatly reduce or eliminate the number of inappropriate referrals to the HES. To achieve the aims of the new GOS contract, four supplementary examinations were introduced: applanation tonometry (either Goldmann or Perkins), dilated indirect fundoscopy, slit lamp biomicroscopy, and threshold VF testing and interpretation. Community optometrists in Scotland were required to attend an 8-hour workshop before they could be accredited with the above four competencies. In addition, the community optometrists were financially reimbursed for every eye patient that they assess for the Scottish NHS (http:/ / www.optometryscotland.org.uk/ article.php?id = 41; accessed September 2007).

A previous study found that despite dissemination of locally agreed guidelines with protocols for referral, there was no improvement in the proportion of falsepositive referrals from optometrists. ${ }^{9}$ A further paper studied the effect of extra training (two 1-hour lectures), standardised referral criteria, and specific ophthalmologist feedback regarding the referrals. ${ }^{10}$ The authors found no significant difference in the positive predictive value of optometrist referrals, and that optometrists only occasionally referred to the guidelines. Not only that it also almost doubled the number of referrals to the HES. ${ }^{10}$

This study shows that after the implementation of the new GOS (Scotland) contract, the quality of referrals from the community optometrists in the northeast of Scotland had improved, certainly at this early stage. The proportion of referrals with applanation IOPs had increased from 11.8 to $50.0 \%$, although there was no statistically significant difference in the proportion of referrals where the IOP was repeated. There may not have been any change in the referrals with VF tests, but those with repeated VFs increased from 14.8 to $28.3 \%$. However, the reduction in referrals with optic disc assessment (from 94.0 to $85.8 \%$ ) and documentation of family history (from 36.6 to $25.8 \%$ ) were statistically significant. It is unknown as to why this may be the case.

The proportion of referrals fulfilling the new contract requirements was $41.7 \%$, indicating that more than half of the referrals were still not adequate. Of the $58.3 \%$ (70 of 120) in the second 6-month study period that did not meet the new contract criteria, $84.3 \%$ (59 of 70) were due to IOP being measured without applanation tonometry. This may be due to the optometrists not having purchased the required equipment, or still being unsure of how to perform applanation tonometry. Optometrists may also not be entirely clear as to what is expected of them under the new contract.

With the improvement in the quality of referrals also came the increase in true-positive referrals (from 18.0 to $31.7 \%$ ) and the decrease in false-positive referrals (from 36.6 to $21.7 \%$ ). There was also a decrease regarding referrals for ocular hypertension (from 29.5 to $7.5 \%$ ), and those discharged by the hospital glaucoma service after the first visit (from 43.2 to $16.7 \%$ ). These figures compare favourably with results from the studies mentioned above. An interesting finding was the reduction in the number of referrals over the two 6-month study periods. This contrasts with the study that found referrals to the HES to almost double after having extra lectures, referral guidelines, and feedback. ${ }^{10}$

In Bristol, specially trained and accredited glaucoma optometrists were shown to perform as well as the routine HES glaucoma review in the management of stable primary open-angle glaucoma and $\mathrm{OHT}$, with no statistically significant difference in outcome. ${ }^{11,12}$

However, the authors found that the optometrists were rather cautious in their approach, with a relatively high proportion of patients being referred back to the HES. ${ }^{12}$ The authors concluded that glaucoma screening through community optometrists would not generate savings, and that shared care schemes were not more costeffective than HES care. ${ }^{12}$ This was in contrast with another report, which found that the accredited glaucoma optometrists reduced the number of glaucomasuspect referrals to the HES by $40 \%$, and was able to save the NHS approximately $£ 17$ per patient. ${ }^{13}$

Although the requirements of the new GOS contract was not intended for community optometrists to become specifically trained in glaucoma screening, the increasing prevalence of glaucoma means that the optometrists will be faced with more and more glaucoma-suspect patients. There may be a role for additional local feedback to the community optometrists to improve the accuracy rates of referrals, and thus, it would be worthwhile repeating the study after these results have been disseminated to the 
northeast of Scotland community optometrists. Whether or not the new GOS (Scotland) contract proves to be cost-effective in the long-term remains to be seen.

\section{Acknowledgements}

We acknowledge the assistance and contributions provided by Mr David Corry, Mr Stephen McPherson, Mr Ian Rough, and Mrs Pat Peacock.

\section{References}

1 National Eye Care Steering Group. Glaucoma sub-group report. In: First Report of the National Eye Care Services Steering Group. Department of Health: London, 2004, pp 1-13.

2 Theodossiades J, Murdoch I. Positive predictive value of optometrist-initiated referrals for glaucoma. Ophthal Physiol Opt 1999; 19(1): 62-67.

3 Bell RWD, O'Brien C. Accuracy of referral to a glaucoma clinic. Ophthal Physiol Opt 1997; 17(1): 7-11.

4 Bell RWD, O'Brien C. The diagnostic outcome of new glaucoma referrals. Ophthal Physiol Opt 1997; 17(1): 3-6.
5 Bowling B, Chen SDM, Salmon JF. Outcomes of referrals by community optometrists to a hospital glaucoma service. $\mathrm{Br} \mathrm{J}$ Ophthalmol 2005; 89: 1102-1104.

6 Vernon SA. The changing pattern of glaucoma referrals by optometrists. Eye 1998; 12: 854-857.

7 Newman DK, Anwar S, Jordan K. Glaucoma screening by optometrists: positive predictive value of visual field testing. Eye 1998; 12(6): 921-924.

8 Lash SC. Assessment of information included on GOS 18 referral form used by optometrists. Ophthal Physiol Opt 2003; 23: 21-23.

9 Vernon SA, Ghosh G. Do locally agreed guidelines for optometrists concerning the referral of glaucoma suspects influence referral practice? Eye 2001; 15: 458-463.

10 Theodossiades J, Murdoch I, Cousens S. Glaucoma case finding: a cluster-randomised intervention trial. Eye 2004; 18: 483-490.

11 Spry PGD, Spencer IC, Sparrow JM, Peters TJ, Brookes ST, Gray $\mathrm{S}$ et al. The Bristol shared care glaucoma study: reliability of community optometric and hospital eye service test measures. Br J Ophthalmol 1999; 83: 707-712.

12 Gray SF, Spry PGD, Brookes ST, Peters TJ, Spencer IC, Baker IA et al. The Bristol shared care glaucoma study: outcome at follow up at 2 years. Br J Ophthalmol 2000; 84: 456-463.

13 Henson DB, Spencer AF, Harper R, Cadman EJ. Community refinement of glaucoma referrals. Eye 2003; 17: 21-26. 